\title{
The Effects of Content Likeability, Content Credibility, and Social Media Engagement on Users' Acceptance of Product Placement in Mobile Social Networks
}

\author{
Ivan Ka Wai Lai ${ }^{1}$ and Yide Liu ${ }^{2}$ \\ ${ }^{1}$ City University of Macau, Faculty of International Tourism and Management, Taipa, Macau, ivanlai@cityu.mo \\ 2 Macau University of Science and Technology, School of Business, Taipa, Macau, ydliu@must.edu.mo
}

Received 29 August 2018; received in revised form 11 June 2019; accepted 1 October 2019

\begin{abstract}
Nowadays, product placements are commonly presented on mobile social media but related studies are rare. The main purpose of the study is to investigate the effects of content likeability, content credibility, and social media engagement on users' acceptance of product placement in mobile social networks. The results of the online survey indicate that content likeability is an antecedent of social media engagement and content credibility; social media engagement has an influence on content credibility; and content likeability, content credibility, and social media engagement both directly affect user acceptance of product placement in mobile social networks. Furthermore, social media engagement has an interaction effect with content likeability on the content credibility of mobile social networks. The results of the multi-group analysis indicate that young adults show differences with middle-aged adults in the direct effect of content likeability on social media engagement and in the interaction effect of content credibility and social media engagement on the acceptance of product placement in mobile social networks. The implications for practitioners are discussed on the basis of the empirical findings.
\end{abstract}

Keywords: Social media engagement, Content credibility, Content likeability, Acceptance of product placements, Mobile social networks 


\section{Introduction}

In the last few years, due to the increasing prevalence of mobile device, mobile social networks (e.g., WhatsApp and WeChat) appeared and led the social media developing trend [83]. Mobile social media enable people to interact with others anytime and become a part of people's daily life nowadays. This trend stimulates marketers to start with product placements through mobile social media. As an advertising method, product placement has existed for more than seventy years [1]. Product placement can be defined as the inclusion of brand or identifiers within mass media programming such as cinema, TV, media vehicles, and video games [51], [52]. However, only a few studies have been conducted on the product placements through social media, especially in mobile social media [51]. Mobile phones allow people immediate access to their social networks and maintain constant contact with others in mobile social networks [40]. There are 1.08 billion active WeChat users in the 3rd quarter of 2018 [75] and 1.5 billion active WhatsApp users in December 2017 [76]. A huge number of mobile phone users attract social media marketers' focus on embedding marketing materials in mobile social media. However, we know little about product placement in mobile social media because there is a lack of research in this area. For improving our knowledge of the consumer behavior reacting to the product placement advertising on the mobile social media, it is essential for researchers to perform empirical studies in this area.

After Facebook introducing the like button, researchers began to study the rise of like economy [22]. If a user likes the content in social media, he/she will endorse that content. Therefore, the number of likes directly links with people's attention to the content [13]. For understanding how to turn a like to a sale, we should investigate how the content likeability influences consumer behavior toward product information posted on social media. The content credibility of an information source is also a strong predictor of an information consumer's further action [58]. Besides, the social media engagement has been demonstrated to greatly influence how individuals perceive media content [2], [78]. Therefore, content likeability, content credibility, and social media engagement may be the factors that influence user behavior towards product placement in mobile social networks. Knowing these relationships, marketers can formulate appropriate strategies to promote their products and services through making product placement in mobile social networks. However, little literature is found in addressing this topic.

In addition, if a user who frequently reads the contents, replies the feedbacks, and posts messages on a social network, the user may perceive the contents in that social network be more likeable and credible. Thus the social media engagement may not only have a direct effect on content credibility but also may moderate the relationship between content likeability and content credibility. Therefore, the second aim of this study is to test the moderating effect of social media engagement on the relationship between content likeability and content credibility. The social media engagement theory stated that higher user engagement leads to greater usage of the social media platform [16]. This study attempts to extend our knowledge in social media engagement theory that content likeability is a source for getting higher user engagement in social media and content credibility is one of the outcomes of user engagement in social media. Social media engagement is a mediator and moderator between content likeability and content credibility.

The previous studies on internet research have heavily focused on the youth segment [49]. It is because young adults (18-30-year-olds) lead the way in adopting internet applications. However, there is an increasing number of middle-aged adults (31-60-year-olds) joining social networks [25]. This middle-aged group earns higher incomes, has more stable jobs, and obtains higher access to credit and debit than youngsters [74]. They have a high purchasing power but may show different behaviors towards the acceptance of the product placement in mobile social networks. Marketers also would like to pay more attention to this group and find out how the factors influence their acceptance of the product placement in mobile social networks. Therefore, the third aim of this study is to bridge the gap and to compare the user behaviors among young adults and middle-aged adults on the acceptance of product placement in mobile social networks. The results of the study contribute to the knowledge in social media marketing as well as in mobile internet research. Practically, this study will provide some useful recommendations for mobile social network marketers to design their product placement advertising.

\section{Research Background}

Relevant literature including product placement, content likeability, social media engagement, and content credibility are presented as follow.

\subsection{Product Placement}

Product placement was born with the birth of motion pictures by the Lumiere brothers in the mid-1890s [40]. Product placement is defined as "the paid inclusion of branded products or brand identifiers, through audio and/or visual means, within mass media programming" [42] p.33. Although product placement is a very old marketing strategy, it is very effective and is still an important topic in marketing research [1]. Product placement ensures that audience cannot easily to avoid advertiser's message because this message is integrated within media content [41]. As placed products are perceived as more natural and credible by the audience, the product placement generates favorable 
consumer associations and goodwill. Also, placements are often more economical than traditional commercials [51]. Although the positioning of product image has extended to the online media [77], researchers are keeping their research focus on traditional media such as movies [56], [59], television shows and operas [17], [50], [61], and video games [15], [21], [57]. Karisik [41] examined 73 studies and found that more than half of studies (38 out of 73 studies) were focused on movie product placements, 19 and 16 studies were on TV and in-game placements respectively. Different researchers have identified various factors that influence product placement effectiveness for these three media.

Compared with the research in traditional media, little research was found in studying the product placement in social media. Recently, Liu, Chou, and Liao [52] conducted field experiments to evaluate the impacts of product prominence and presentation on the effectiveness of product placement in social media in Taiwan. They found that product placement conducts (product prominence and presentation) in social media are similar to the effect of product placement in other media. They also suggested that product placement on a higher brand awareness vehicle would have better results. Furthermore, Gageler and van der Schee [20] took an online survey in Sweden and found that product placement in social media has a positive influence on brand perception and purchase intention. Although these two studies both focused on the brand, Liu et al. [52] studied brand awareness as an antecedent of the effectiveness of product placement, however, Gageler and van der Schee [20] considered brand perception as the outcome of product placement in social media. But there is a lack of research other than brand-related topics.

Nowadays, more and more people are using mobile social networks. Many marketers have placed their brands and products in different forms of contents in mobile social networks. In order to push potential customers' awareness and interest, marketers use different accounts to routinely write the posts, broadcast messages to groups, give the likes, and reply positive comments in a short period of time. As the results, some marketers successfully promote their brands and products by adopting product placements [56], but some fail because users do not accept their product placement in mobile social networks. Therefore, there is a need to find out the ways that influence user acceptance of product placement in mobile social networks.

\subsection{Content Likeability}

In the Oxford living dictionaries, the definition of likeable is '(especially of a person) pleasant, friendly, and easy to like' [62]. For the psychological studies, likeability is the positive first impressions of a person that often lead to more positive evaluations of that person [70]. It reflects the acceptance and preference of a person [23] and is referred to as a scheme of self-presentation to persuade people [10], [43]. Since the judgments of likeability are generally not made on the basis of a sole factor [80], researchers have developed different measurement scales to make the liking judgements of a person [60], [68]. In 2009, Facebook introduced a like button that enables users to easily express their likeability emotions. People will give a like if they prefer a message on the Facebook. The use of the like button became the most popular Facebook activities [29]. At the same time, people want to have their posted contents be liked. People accept this like concept, so new developed social media also provide this feature. Such that, the terms likeability was then extended from liking judgement of a person to liking judgements of the contents on social media. Therefore, content likeability is a way of evaluating the information value of the content on social media.

\subsection{Social Media Engagement}

Engagement was first conceptualized by Kahn [39] in 1990 and increasingly used in the broader academic marketing literature [5]. Customer engagement is a psychological state that occurs by virtue of interactive customer experiences with a focal agent/object, such as a firm or brand [5]. According to Brodie et al. [5], [6], customer engagement represents a highly context-dependent psychological state, characterized by a specfic intensity level that plays a center role in the process of relational exchange. Previous studies about customer engagement are mainly focused on the interactions between a customer and an organization [32], [65], a customer and a product [64] and a customer and a brand [31], [73]. Due to the rapid development of internet applications, recent studies in customer engagement are shifted to online areas such as virtual/online brand community [6], [14], online platform [9], social media [11], [32], tourism organizations on social media [19], social TV websites [63], tourism brands [73], company social networks [84], nonprofit organizations on social network sites [35], mobile devices for shopping [79], and social networking sites [55]. Among these online topics, social media become a popular one because social media allow the creation and exchange of user-generated content [38], so they facilitate two-way interactions between users. On social media, engagement is measured in interactions with others [34]. Thus, social media engagement is about the interactions between users in social networks. With the growth of mobile phones, people like to use mobile apps. Kim, Lin, and Sung [44] p.54 explained the concept of mobile app engagement as a set of branded app experiences that motivates consumers to try to make happen repeatedly in their lives. People then move from traditional social media platforms to mobile social media platforms because mobile social networks can connect people anywhere. Although there are a number of studies in customer/user engagement in social networks, the studies in mobile social networks are less. Compared with traditional social media, people have more control over the content on mobile social networks [26], the mechanism of mobile social media engagement is believed to be different from that of traditional social media engagement [83]. Thus, this study attempts to understand the causes and consequences of mobile social media engagement regarding product placement in mobile social networks. 


\subsection{Content Credibility}

Credibility of an advertisement is the degree to which the consumer perceives claims made about the brand in the advertising to be truthful and believable [53]. This problem is becoming even more severe on the Internet, where an increasing number of messages coming from self-publishing [51]. Since credibility is not only related to the product being advertised, but also to the medium through which the message is being delivered [66], Kiousis [45] further defined advertising medium credibility in terms of consumers' perceptions of the average believability of a channel's overall advertising content. Hughes et al. [33] mentioned that given the prevalence of online media today, credibility continues to be a popular subject of empirical research. Over the years, a number of studies have attempted to assess consumers' perceptions of credibility of various online social media such as websites [18], [51], blogs [54], Twitter [71], and Facebook [48].

Comparing the credibility of traditional and online media, Prendergast, Liu, and Poon [66] found that the broadcast media (radio, broadcast television, and cable television) were considered as the most credible advertising media, while direct mail and the internet were considered as the least credible. Recently, Johnson and Kaye [36] compared perceptions of credibility of political information found on Facebook, blogs, and Twitter to credibility of information found on traditional media. They made similar conclusions that all traditional media except Fox News were rated more credible than social media sites. They further tested the credibility of mobile news apps with other online social media (social network sites, Twitter, and YouTube), traditional media, nontraditional media, and traditional partisan sources [37]. They found that interactivity with mobile applications would lead to perceptions of high credibility.

\section{Research Method}

Based on the findings from the literature, hypotheses to be tested in the research model are formulated. Measurement instrument and data collection method are shown as follow.

\subsection{Hypothesis Development}

Product placement in social media consists of a writer producing some engaging contents (e.g. an article) incorporated with a promotional message (e.g. a picture that includes product information) in order to promote the product [52]. Users will feel positive about product placement in a mobile social network in case they like the contents on the network. Thus, the content likeability may affect user acceptance of product placement in the mobile social network.

H1a: Content likeability has a positive influence on user acceptance of product placement in the mobile social network.

Social mobile apps (e.g., WhatsApp and WeChat) enable users to create a mobile social network with friends and communicate with them anytime and anywhere. People like to post and read messages (texts, photos, and videos) in the mobile social networks. In case people like the contents in a mobile social network, they will frequently check the messages and promptly reply the messages with a like. Each click on the like button may trigger more engagement between the users in the mobile social network [82]. Han and Trimi [30] used the total of likes divided by a total fan count to measure the engagement rate. The more the like contents in a social network, the more engagement people will present.

\section{H1b: Content likeability has a positive influence on the social media engagement of the mobile social network.}

Shavitt and Brock [72] mentioned that we believe people who we like, instead of the ones we dislike. Brodsky et al. [7] also argued that likeability is positively associated with credibility. Thus, a member who likes the contents on a mobile social network, he/she may believe the contents of the network more.

H1c: Content likeability has a positive influence on the content credibility of the mobile social network.

An engaged user in a social network shows a set of actions that include reacting to contents, commenting on contents, sharing contents with others, and posting user-generated contents [3]. These contents may incorporate with some promotional messages [52]. Recently, Wu [83] tested the relationship between mobile social network engagement and advertising effectiveness. He found that mobile social media engagement positively influences perceived advertising value, which in turn predicts consumers' intention to accept advertisements in mobile social media. Although product placement is not an explicit advertisement, social media engagement may influence the consumer acceptance of product placement in mobile social networks.

H2: Social media engagement has a positive influence on user acceptance of product placement in the mobile social network. 
Media engagement comes from experiencing media content [8]. It is a psychological state that occurs by virtue of interactive effects [5]. Greer [24] reported that the amount of time we spend online is the strongest predictor of whether the online medium could be judged as credible. Therefore, if a user who spends more time in a mobile social network, he/she will judge the contents of the mobile social network be more believable.

\section{H3: Social media engagement has a positive influence on the content credibility of the mobile social network.}

Tseng and Fogg [81] explained that credibility will lead to believability. Then, a credible content is a believable content. Therefore, once the users perceive that the contents of a mobile social network are credible, they will believe the contents that include product placement in the network. Then, they may accept the product placement in the network.

\section{H4: Content credibility has a positive influence on user acceptance of product placement in the mobile social network.}

A moderator variable changes the strength of a relationship between two constructs in the model, so when modeling moderating effects, the moderator's measurement model is included twice in the model as in the interaction term [28] Since a mobile social network is a type of interactive media that aim to engage users in instant social interactions. However, different participants involve different levels of engagement in the mobile social networks. According to the social media engagement theory, the more frequently users take part in a social media site, the more exploration of contents users can get within the social media site [16], then, they will find more likeable contents and credible contents in the social media site. Such that, the participants who have a higher level of engagement in a mobile social network, the effect of content likeability on the content creditability of the mobile social network may be higher.

H5a: Social media engagement has an interaction effect with content likeability on the content credibility of the mobile social network.

Furthermore, the participants who have different levels of engagement in a mobile social network, the effects of content likeability and content credibility on the acceptance of product placement in the mobile social network may vary. Therefore, social media engagement may have interaction effects with content likeability and content credibility on the user acceptance of product placement in the mobile social networks. Figure 1 shows the research model of this study.

H5b: Social media engagement has an interaction effect with content likeability on the user acceptance of product placement in the mobile social network.

H5c: Social media engagement has an interaction effect with content credibility on the user acceptance of product placement in the mobile social network.

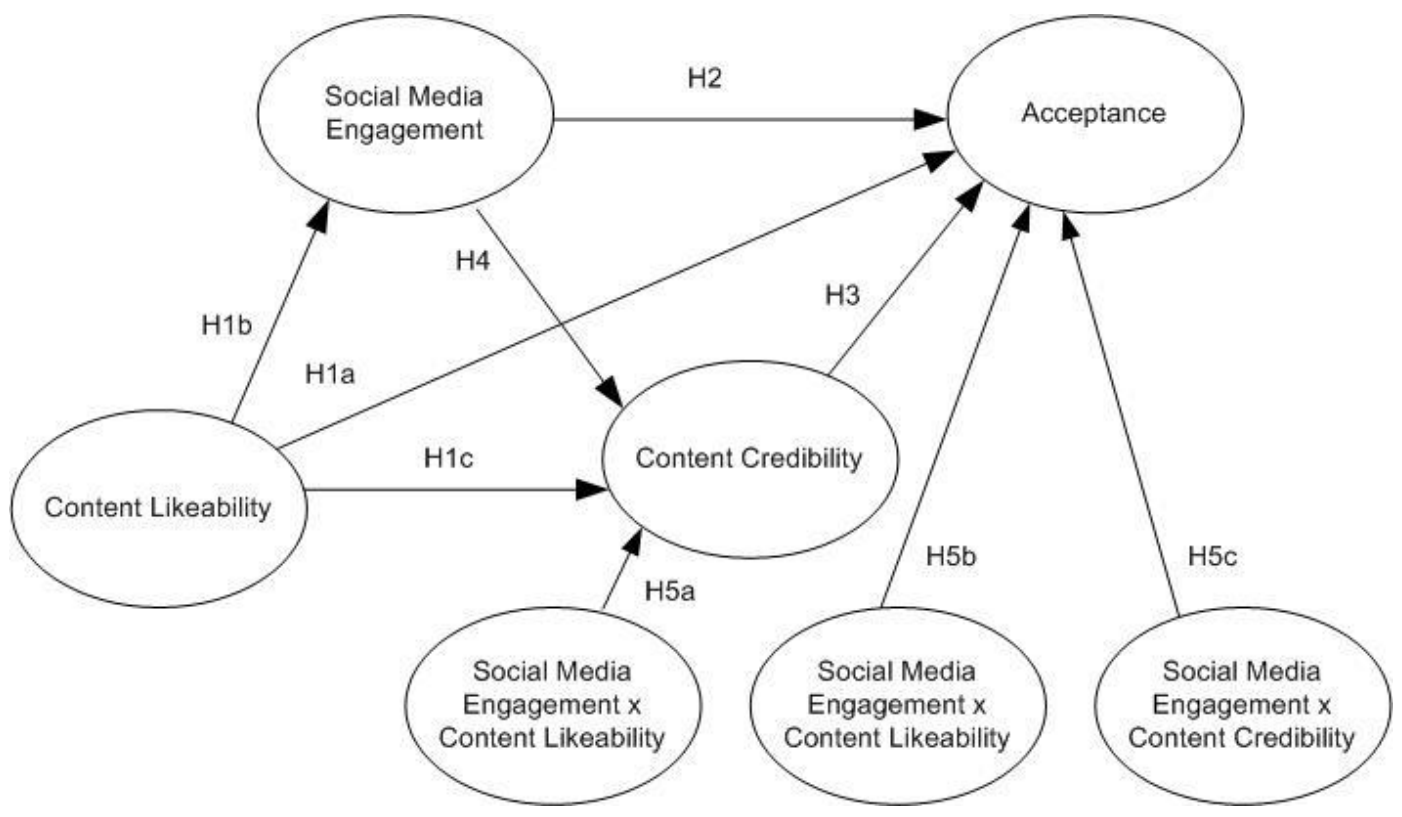

Figure 1: Research model 


\subsection{Measurement Instrument}

A measurement scale for content likeability of mobile social networks was developed that include six items as: The contents on my WeChat groups are valuable, wonderful, personally agreeable, impressive, useful, and warm. The details of development processes were shown in Appendix A. Since a mobile social network is a medium, so the content credibility of a mobile social network is defined in terms of users' perceptions of believability of the contents of the mobile social networks. Therefore, the measurable items of content credibility are revised from Prendergast et al.'s [66] study such as I think the contents on my WeChat groups are believable. For the social media engagement and acceptance of product placement in the mobile social network, the measurable items are taken from Wu's [81] study. In this study, social media engagement in a mobile social network is about the interactions between users in the mobile social network, so the social media engagement can be measured as I always use my mobile phone to check the messages from my WeChat groups. As Wu's [83] study, this study measures the acceptance rather than actual behaviors because, for self-report empirical studies, it is hard to measure respondents' actual actions regarding product placement advertising. The acceptance of product placement in a mobile social network is directly measured as I will accept product placements on my WeChat groups in the future. The questionnaire was designed in English. Then, these measurement scales were sent to two professors in electronic commerce to validate their contents. The refined version was translated into Chinese. Double translation in Chinese was performed to validate the Chinese version of the questionnaire.

\subsection{Questionnaire Survey}

An online questionnaire survey was conducted to examine the relationships between content likeability, content credibility, social media engagement, and the acceptance of product placement in mobile social networks. The questionnaire consists of three sections. The first section provides different examples of product placement in mobile social networks (as shown in Figure in Appendix B). This setting aims to refresh respondents' memory in product placements that they have experienced in mobile social networks before. A filter question is used to confirm respondents feel confident to complete the questionnaire. The second section contains 15 questions regarding the research modelling constructs as shown in Table 2. A 7-point Likert scale (ranging from $1=$ strongly disagree to $7=$ strongly agree) is designed to ask the respondents to rate these 15 questions. The final section is the respondents' general contextual background information including gender, age, education, monthly income, and career.

A face-to-face pilot test was conducted with 30 WeChat users to validate the content of the questionnaire in April 2017. With examples of product placement in WeChat, the respondents reported that the questions were not difficult to understand and answer. After completing the pilot test, the questionnaire was distributed through WeChat and SoJump (online survey platform) between May and June 2017. Totally 502 samples were collected, but only 448 questionnaires were valid for data analysis because 54 were found to be unusable for which respondents gave the same rating for all of the questions. Table 1 shows the detailed background information of the respondents. Over half of the respondents were middle-aged adults $(50.89 \%, 228)$ and $48.66 \%(218)$ of respondents were young adults. The sample sizes of these two groups are larger than 10 times the number of indicators, so both sample sizes should be adequate [4].

Table 1: Summary of respondent background $(n=448)$

\begin{tabular}{|c|c|c|c|c|c|c|c|}
\hline & & \multicolumn{2}{|l|}{ All $(n=448)$} & \multicolumn{2}{|c|}{ Young adults $(n=218)$} & \multicolumn{2}{|c|}{ Middle-aged adults $(n=228)$} \\
\hline & & Frequency & $\%$ & Frequency & $\%$ & Frequency & $\%$ \\
\hline \multirow[t]{2}{*}{ Gender } & Males & 183 & 40.8 & 68 & 31.2 & 113 & 49.6 \\
\hline & Females & 265 & 59.2 & 150 & 68.8 & 115 & 50.4 \\
\hline \multirow[t]{3}{*}{ Age } & $18-30$ & 218 & 48.7 & 218 & 100 & & \\
\hline & $31-60$ & 228 & 50.9 & & & 228 & 100 \\
\hline & Over 60 & 2 & 0.4 & & & & \\
\hline \multirow[t]{4}{*}{ Education } & Junior secondary & 6 & 1.3 & 0 & 0.0 & 6 & 2.6 \\
\hline & Senior secondary & 24 & 5.4 & 9 & 4.1 & 14 & 6.1 \\
\hline & Undergraduate & 374 & 83.5 & 181 & 83.0 & 193 & 84.6 \\
\hline & Postgraduate & 44 & 9.8 & 28 & 12.8 & 15 & 6.6 \\
\hline Monthly & 225 or under & 57 & 12.7 & 55 & 25.2 & 2 & 0.9 \\
\hline income & $226-395$ & 34 & 7.6 & 16 & 7.3 & 16 & 7.0 \\
\hline \multirow[t]{5}{*}{ (USD) } & $396-565$ & 86 & 19.2 & 57 & 26.1 & 29 & 12.7 \\
\hline & $566-900$ & 151 & 33.7 & 55 & 25.2 & 96 & 42.1 \\
\hline & $901-1355$ & 71 & 15.8 & 17 & 7.8 & 54 & 23.7 \\
\hline & $1356-1690$ & 22 & 4.9 & 8 & 3.7 & 14 & 6.1 \\
\hline & Over 1690 & 27 & 6.0 & 10 & 4.6 & 17 & 7.6 \\
\hline \multirow[t]{3}{*}{ Career } & Student & 71 & 15.8 & 71 & 32.6 & 0 & 0.0 \\
\hline & Education & 62 & 13.8 & 29 & 13.3 & 33 & 14.5 \\
\hline & Agriculture & 4 & 0.9 & 4 & 1.8 & 0 & 0.0 \\
\hline
\end{tabular}




\begin{tabular}{|c|c|c|c|c|c|c|c|}
\hline \multicolumn{8}{|c|}{ Table 1: continuation } \\
\hline & Business & 55 & 12.3 & 25 & 11.5 & 30 & 13.2 \\
\hline & Retails & 37 & 8.3 & 16 & 7.3 & 21 & 9.2 \\
\hline & Manufacturing & 114 & 25.4 & 35 & 16.1 & 79 & 34.6 \\
\hline & IT & 47 & 10.5 & 17 & 7.8 & 30 & 13.2 \\
\hline & Government & 29 & 6.5 & 9 & 4.1 & 20 & 8.8 \\
\hline & No & 8 & 1.8 & 3 & 1.4 & 3 & 1.3 \\
\hline & Others & 21 & 4.7 & 9 & 4.1 & 12 & 5.3 \\
\hline
\end{tabular}

\section{Findings}

The results of data analysis including the test of reliability and construct validity, PLS regression analysis, and multigroup analysis are provided as follow.

\subsection{Reliability and Construct Validity}

Table 2 shows the mean, standard deviation, and factor loading for each measurable item. Table 3 shows the values of Cronbach's alpha, Average Variance Extracted (AVE), Construct Reliability (CR), and correlation of each construct. The values of Cronbach's alpha, AVE, and CR for all constructs exceed $0.7,0.5$, and 0.7 respectively. The square root of each AVE is larger than its construct correlations. The values of Heterotrait-Monotrait ratio are lower than 0.85. These results confirm the reliability and validity of the data. Table 4 shows the results of collinearity statistics. Since all the values of Variance Inflation Factor (VIF) are smaller than 3.3, there is no multicollinearity issue [46].

Table 2: Mean, standard deviation, and factor leading of each measurable item

\begin{tabular}{|l|l|l|l|l|}
\hline & Measured Item & Mean & $\begin{array}{l}\text { Std. } \\
\text { Dev. }\end{array}$ & $\begin{array}{l}\text { Factor } \\
\text { Loading }\end{array}$ \\
\hline & Content Likeability (L) & & \\
\hline L1 & The contents on my WeChat groups are valuable. & 4.775 & 1.163 & 0.849 \\
\hline L2 & The contents on my WeChat groups are wonderful. & 4.973 & 1.161 & 0.859 \\
\hline L3 & The contents on my WeChat groups are personally agreeable. & 5.002 & 1.099 & 0.827 \\
\hline L4 & The contents on my WeChat groups are Impressive. & 4.911 & 1.165 & 0.883 \\
\hline L5 & The contents on my WeChat groups are useful. & 5.004 & 1.120 & 0.874 \\
\hline L6 & The contents on my WeChat groups are warm. & 5.036 & 1.095 & 0.841 \\
\hline & Social Media Engagement (E) - adapted from Wu [83] & & \\
\hline E1 & My WeChat groups often give me something to talk about. & 5.346 & 0.903 & 0.812 \\
\hline E2 & $\begin{array}{l}\text { I always use my mobile phone to check the messages from my WeChat } \\
\text { groups. }\end{array}$ & 5.833 & 1.000 & 0.732 \\
\hline E3 & I always pay attention to the messages on my WeChat groups. & 5.395 & 1.103 & 0.877 \\
\hline & Content Credibility (C) - adapted from Prendergast et al. [66] & & \\
\hline C1 & I think the contents on my WeChat groups are credible. & 4.540 & 1.209 & 0.910 \\
\hline C2 & I think the contents on my WeChat groups are not exaggerated. & 4.393 & 1.226 & 0.911 \\
\hline C3 & I think the contents on my WeChat groups are believable. & 4.500 & 1.241 & 0.909 \\
\hline & Acceptance (A) - adapted from Wu [83] & & \\
\hline A1 & $\begin{array}{l}\text { I am willing to receive product placements on my WeChat groups in the } \\
\text { future. }\end{array}$ & 4.511 & 1.397 & 0.920 \\
\hline A2 & $\begin{array}{l}\text { I would read product placements messages I receive in my WeChat groups } \\
\text { in the future. }\end{array}$ & 4.801 & 1.288 & 0.917 \\
\hline A3 & I will accept product placements on my WeChat groups in the future. & 4.625 & 1.365 & 0.928 \\
\hline
\end{tabular}

Table 3: Reliability, validity, correlations and square roots of AVEs

\begin{tabular}{|c|c|c|c|c|c|c|c|c|c|c|}
\hline & \multirow{2}{*}{$\begin{array}{l}\text { Cronbach' } \\
\text { s Alpha }\end{array}$} & \multirow{2}{*}{ AVE } & \multirow{2}{*}{ CR } & \multicolumn{4}{|c|}{ Fronell-Larcker Criterion } & \multicolumn{3}{|c|}{ Heterotrait-Monotrait Ratio } \\
\hline & & & & $\mathrm{L}$ & $E$ & $\mathrm{C}$ & $A$ & $\mathrm{~L}$ & $E$ & $\mathrm{C}$ \\
\hline $\begin{array}{l}\text { Content } \\
\text { Likeability (L) }\end{array}$ & 0.927 & 0.732 & 0.942 & 0.856 & & & & & & \\
\hline $\begin{array}{l}\text { Social Media } \\
\text { Engagement } \\
\text { (E) }\end{array}$ & 0.746 & 0.654 & 0.850 & 0.594 & 0.809 & & & 0.671 & & \\
\hline $\begin{array}{l}\text { Content } \\
\text { Credibility (C) }\end{array}$ & 0.896 & 0.828 & 0.935 & 0.721 & 0.504 & 0.910 & & 0.789 & 0.572 & \\
\hline Acceptance (A) & 0.911 & 0.849 & 0.944 & 0.715 & 0.550 & 0.711 & 0.922 & 0.775 & 0.631 & 0.783 \\
\hline
\end{tabular}


Table 4: Collinearity statistics (VIF values)

\begin{tabular}{|l|l|l|l|}
\hline & Acceptance & Content Credibility & $\begin{array}{l}\text { Social Media } \\
\text { Engagement }\end{array}$ \\
\hline Content Credibility $\times$ Social Media Engagement & 1.998 & & \\
\hline Content Credibility & 2.220 & & \\
\hline Social Media Engagement & 1.707 & 1.626 & \\
\hline Content Likeability $\times$ Social Media Engagement & 2.225 & 1.170 & \\
\hline Content Likeability & 2.660 & 1.576 & 1.000 \\
\hline
\end{tabular}

\subsection{Results of PLS analysis}

A partial least squares (PLS) analysis was conducted because it is better suited for presenting the moderating effects [47]. As recommended by Hair et al. [27], bootstrapping using 448 cases and 5000 samples was performed to assess the path coefficients' significance for the research model. Figure 2 shows the results of PLS analysis by using the SmartPLS v.3.2.6 package [69]. In summary, content likeability has an influence on content credibility $(\beta=0.677$, t-statistics $=16.132)$ and social media engagement $(\beta=0.594$, t-statistics $=17.822)$; social media engagement has an influence on content credibility $(\beta=0.157$, t-statistics $=3.165)$; and content likeability, content credibility, and social media engagement directly affect user acceptance of product placement in mobile social networks $(\beta=0.354$, t-statistics $=6.873 ; \beta=0.385$, t-statistics $=7.761 ; \beta=0.142$, t-statistics $=3.479$ ). The values of $R$-square of social media engagement, content credibility, and acceptance are $0.353,0.549$, and 0.606 respectively. Thus, hypotheses $\mathrm{H} 1, \mathrm{H} 2, \mathrm{H} 3$, and $\mathrm{H} 4$ are supported. Furthermore, the interaction effect of content likeability $x$ social media engagement on content credibility is significant $(\beta=0.140$, t-statistics $=3.166)$, hypothesis $\mathrm{H} 5 \mathrm{a}$ is supported. However, $\mathrm{H} 5 \mathrm{~b}$ and $\mathrm{H} 5 \mathrm{c}$ are rejected. Figure 3 shows the results of a simple slope analysis of the interaction effect of content likeability $x$ social media engagement on content credibility. Table 5 shows the effects of exogenous constructs on endogenous constructs. The values of $f$-square for all significant paths are higher than 0.02 . There is no omitted exogenous construct from the model [28].

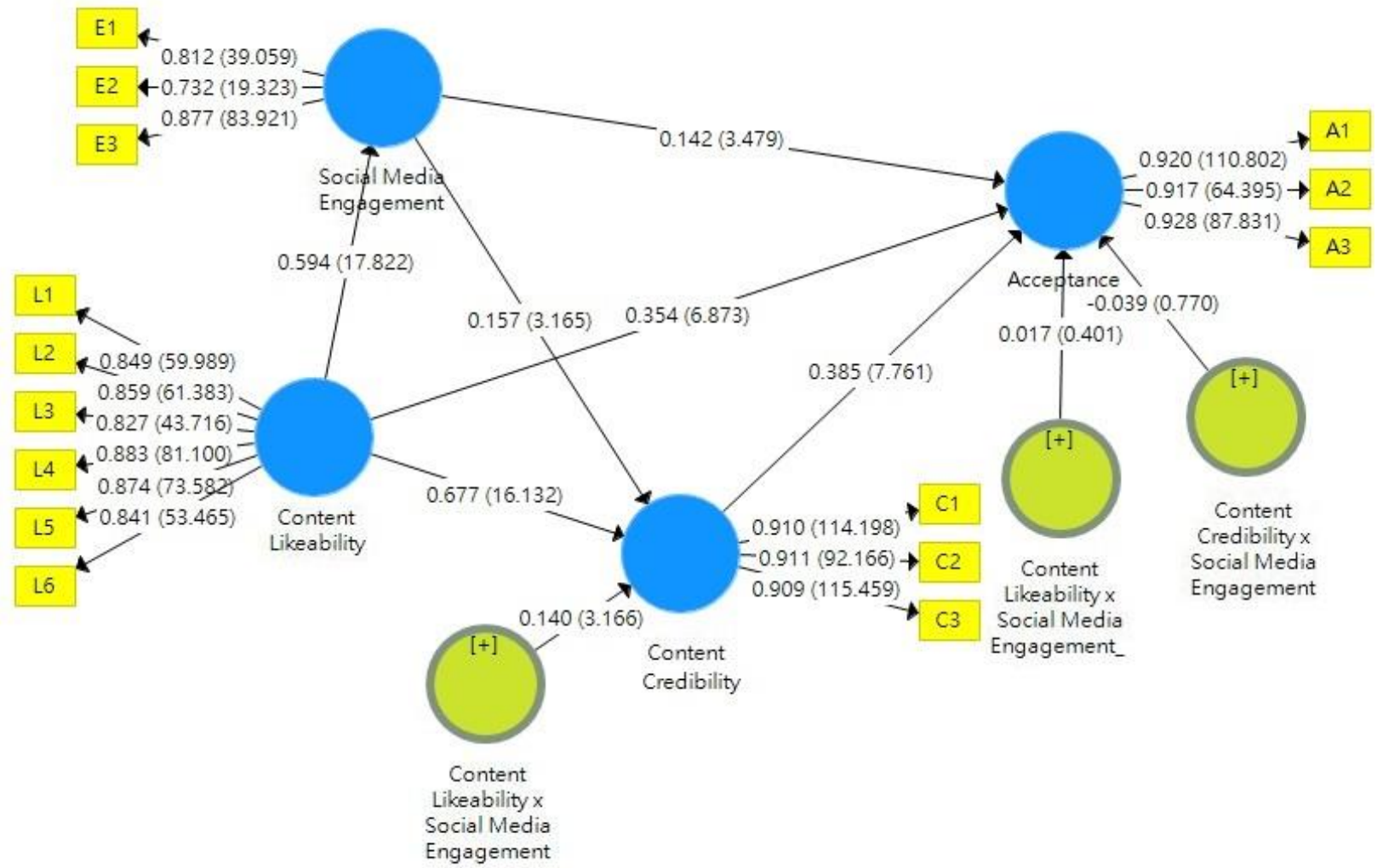

Figure 2: Results of PLS analysis $(n=448)$ 


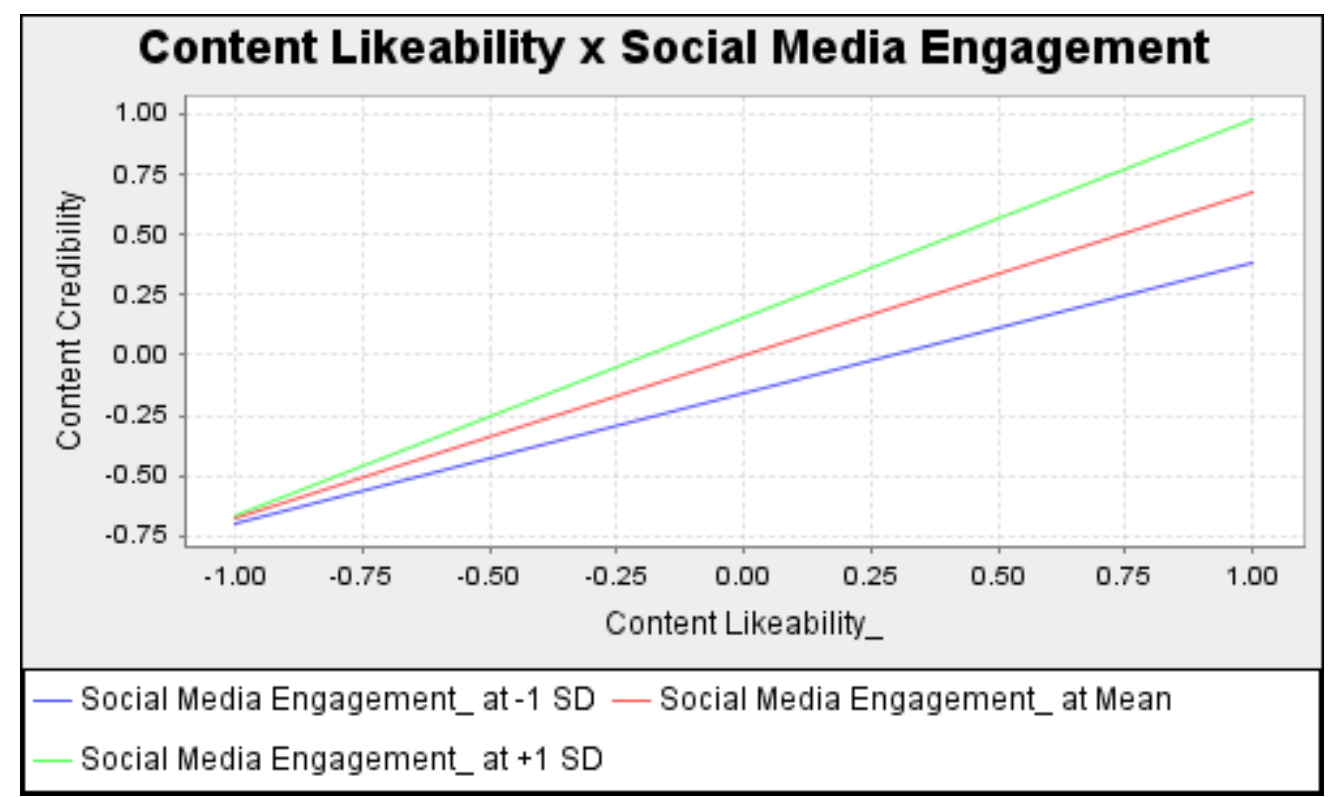

Figure 3: Interaction effect of Content Likeability x Social Media Engagement on Content Credibility

Table 5: The Values of R-square and f-square

\begin{tabular}{|l|l|l|l|}
\hline \multicolumn{1}{|l|}{} & Acceptance & Content Credibility & Social Media Engagement \\
\hline R-square & 0.606 & 0.549 & 0.353 \\
\hline & f-square & \\
\hline Content Credibility x Social Media Engagement & 0.002 & \multicolumn{2}{l|}{} \\
\hline Content Credibility & 0.170 & & \\
\hline Social Media Engagement & 0.030 & 0.034 & \\
\hline Content Likeability x Social Media Engagement & 0.000 & 0.046 & \\
\hline Content Likeability & 0.120 & 0.645 & 0.545 \\
\hline
\end{tabular}

Table 6: Mean, standard deviation, and factor leading of each measurable item

\begin{tabular}{|l|l|l|l|l|l|l|}
\hline \multirow{2}{*}{ Item } & \multicolumn{3}{|l|}{ Young Adults $(\mathrm{n}=218)$} & \multicolumn{3}{l|}{ Middle-aged Adults $(\mathrm{n}=228)$} \\
\cline { 2 - 7 } & Mean & St. Dev. & Factor Loading & Mean & St. Dev. & Factor Loading \\
\hline L1 & 4.564 & 1.149 & 0.852 & 4.974 & 1.147 & 0.843 \\
\hline L2 & 4.812 & 1.229 & 0.880 & 5.127 & 1.075 & 0.827 \\
\hline L3 & 4.835 & 1.157 & 0.854 & 5.167 & 1.017 & 0.784 \\
\hline L4 & 4.679 & 1.237 & 0.902 & 5.136 & 1.049 & 0.846 \\
\hline L5 & 4.757 & 1.165 & 0.894 & 5.246 & 1.022 & 0.835 \\
\hline L6 & 4.830 & 1.167 & 0.847 & 5.232 & 0.984 & 0.820 \\
\hline E1 & 5.197 & 0.935 & 0.767 & 5.482 & 0.845 & 0.847 \\
\hline E2 & 5.761 & 1.031 & 0.734 & 5.899 & 0.970 & 0.739 \\
\hline E3 & 5.115 & 1.173 & 0.882 & 5.654 & 0.959 & 0.861 \\
\hline C1 & 4.362 & 1.282 & 0.923 & 4.711 & 1.114 & 0.888 \\
\hline C2 & 4.234 & 1.287 & 0.919 & 4.553 & 1.144 & 0.899 \\
\hline C3 & 4.248 & 1.254 & 0.918 & 4.746 & 1.183 & 0.896 \\
\hline A1 & 4.376 & 1.448 & 0.911 & 4.640 & 1.339 & 0.927 \\
\hline A2 & 4.683 & 1.291 & 0.917 & 4.917 & 1.280 & 0.917 \\
\hline A3 & 4.477 & 1.385 & 0.918 & 4.768 & 1.336 & 0.936 \\
\hline
\end{tabular}

\subsection{Results of Multi Group Analysis}

For achieving the third aim of this study, a multi-group analysis was conducted by using PLS-MGA [28] to examine the differences between two groups of people (young and middle-aged adults). Table 6 shows the mean, standard deviation, and factor leading of each measurable item for these two groups. Table 7 shows the construct reliability, validity, and discriminant validity of two groups of data. These results confirm the reliability and validity of two groups of data. Table 8 shows the results of multi-group analysis. All paths except the interaction effects in the structural model are significant for both young and middle-aged adults (as shown in Figure 4). For the young group, the interaction effect of content likeability $x$ social media engagement on content credibility is significant $(\beta=0.104$, $t$ - 
statistics $=2.270)$. For the middle-aged group, the interaction effects of content likeability $\times$ social media engagement on content credibility and content credibility $x$ social media engagement on acceptance are significant $(\beta=0.169$, tstatistics $=2.446 ; \beta=-0.121$, t-statistics $=2.250$ ). The results of PLS-MGA also indicate that the differences of path coefficients of content likeability on social media engagement and content credibility $x$ social media engagement on acceptance are significant (coefficients-diff $=0.142$, $p$-value $=0.020$; coefficients-diff $=0.189, p$-value $=0.035$ ).

Table 7: Reliability, validity, correlations and square roots of AVEs

\begin{tabular}{|c|c|c|c|c|c|c|c|}
\hline & Cronbach's Alpha & AVE & CR & $\mathrm{L}$ & $E$ & $\mathrm{C}$ & $\mathrm{A}$ \\
\hline & \multicolumn{7}{|l|}{ Young adults } \\
\hline Content Likeability (L) & 0.937 & 0.760 & 0.950 & 0.872 & & & \\
\hline Social Media Engagement (E) & 0.725 & 0.635 & 0.838 & 0.643 & 0.797 & & \\
\hline Content Credibility (C) & 0.909 & 0.846 & 0.943 & 0.737 & 0.548 & 0.920 & \\
\hline \multirow[t]{2}{*}{ Acceptance $(\mathrm{A})$} & 0.903 & 0.838 & 0.939 & 0.761 & 0.592 & 0.718 & 0.915 \\
\hline & \multicolumn{7}{|l|}{ Middle-aged adults } \\
\hline Content Likeability (L) & 0.907 & 0.682 & 0.928 & 0.826 & & & \\
\hline Social Media Engagement (E) & 0.759 & 0.668 & 0.857 & 0.501 & 0.817 & & \\
\hline Content Credibility (C) & 0.875 & 0.800 & 0.923 & 0.678 & 0.418 & 0.894 & \\
\hline Acceptance $(\mathrm{A})$ & 0.918 & 0.859 & 0.948 & 0.663 & 0.493 & 0.698 & 0.927 \\
\hline
\end{tabular}

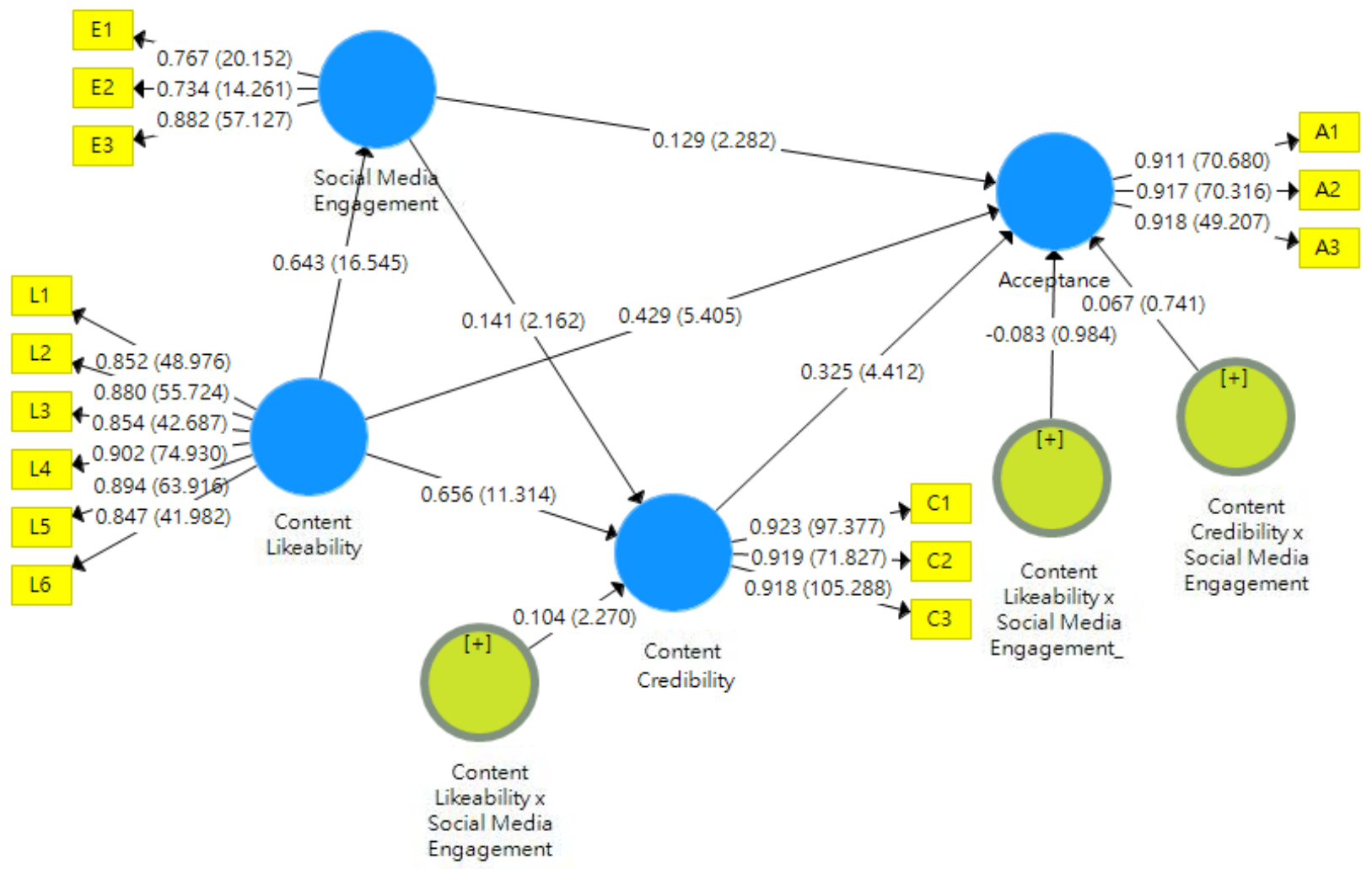

(a) Young adults $(\mathrm{n}=218)$ 


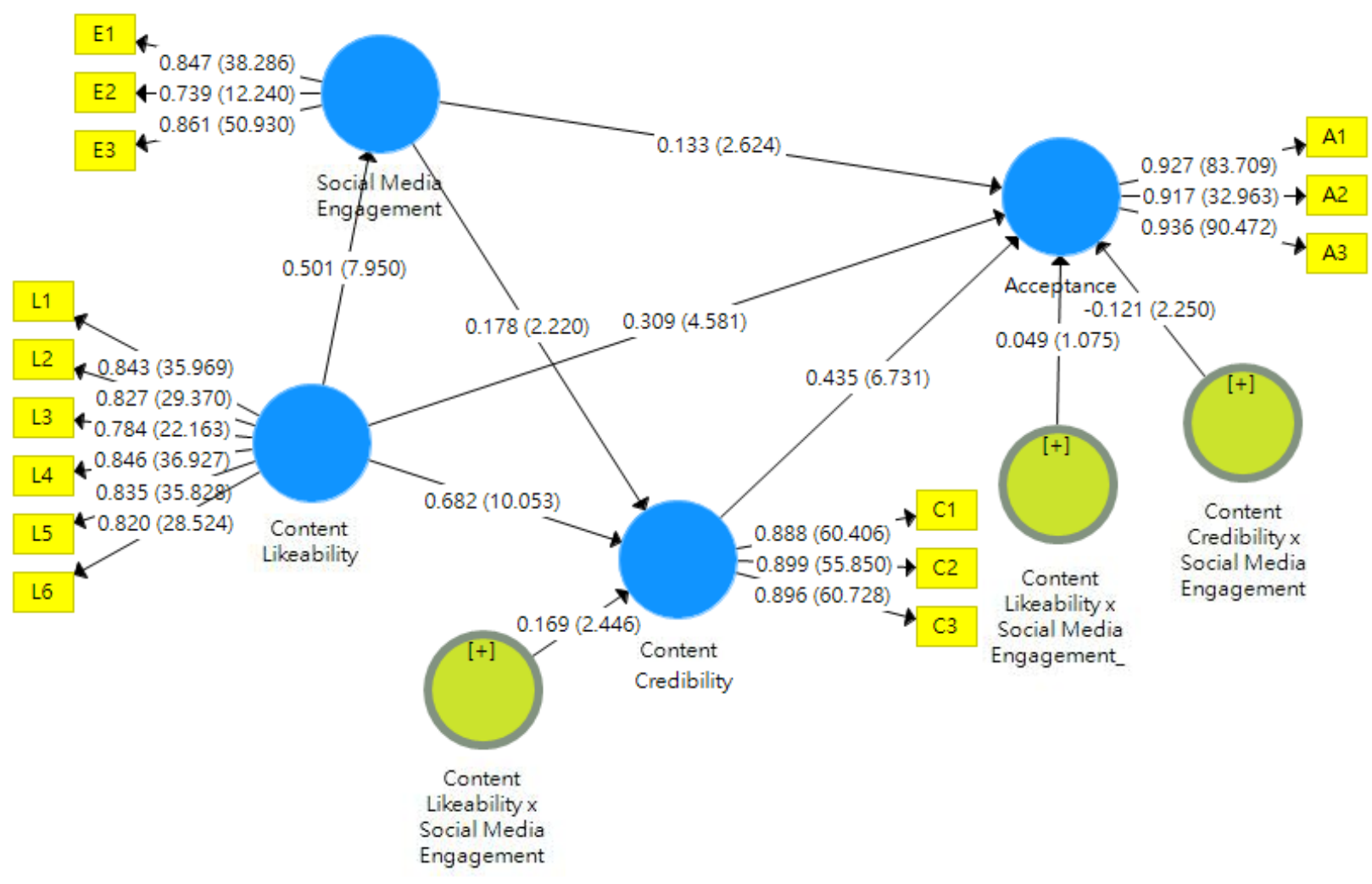

(b) Middle-aged adults $(\mathrm{n}=228)$

Figure 4: Results of PLS analysis of young and middle-aged adults

Table 8: Multi-group analysis

\begin{tabular}{|c|c|c|c|c|c|c|}
\hline & \multicolumn{2}{|c|}{$\begin{array}{l}\text { Young Adults } \\
(\mathrm{n}=218)\end{array}$} & \multicolumn{2}{|c|}{$\begin{array}{l}\text { Middle-aged Adults } \\
(\mathrm{n}=228)\end{array}$} & \multicolumn{2}{|c|}{ PLS-MGA } \\
\hline & R-square & & R-square & & & \\
\hline Acceptance & 0.646 & & 0.586 & & & \\
\hline Content Credibility & 0.562 & & 0.511 & & & \\
\hline \multirow{2}{*}{ Social Media Engagement } & 0.414 & & 0.251 & & & \\
\hline & coefficient & t-value & coefficient & $\mathrm{t}$-value & coef diff & $p$-value \\
\hline $\begin{array}{l}\text { Content Credibility x Social Media } \\
\text { Engagement } \rightarrow \text { Acceptance }\end{array}$ & 0.067 & 0.731 & $-0.121^{*}$ & 2.22 & $0.189^{*}$ & 0.035 \\
\hline Content Credibility $\rightarrow$ Acceptance & $0.325^{\star \star \star}$ & 4.397 & $0.435^{\star \star \star}$ & 6.772 & 0.109 & 0.867 \\
\hline $\begin{array}{l}\text { Social Media Engagement } \rightarrow \\
\text { Acceptance }\end{array}$ & $0.129^{*}$ & 2.288 & $0.133^{\star *}$ & 2.595 & 0.004 & 0.521 \\
\hline $\begin{array}{l}\text { Social Media Engagement } \rightarrow \text { Content } \\
\text { Credibility }\end{array}$ & $0.141^{*}$ & 2.145 & $0.178^{*}$ & 2.333 & 0.038 & 0.644 \\
\hline $\begin{array}{l}\text { Content Likeability } \times \text { Social Media } \\
\text { Engagement } \rightarrow \text { Content Credibility }\end{array}$ & $0.104^{*}$ & 2.262 & $0.169^{*}$ & 2.468 & 0.065 & 0.785 \\
\hline $\begin{array}{l}\text { Content Likeability x Social Media } \\
\text { Engagement } \rightarrow \text { Acceptance }\end{array}$ & -0.083 & 0.994 & 0.049 & 1.096 & 0.132 & 0.922 \\
\hline Content Likeability $\rightarrow$ Acceptance & $0.429^{\star \star *}$ & 5.384 & $0.309^{* \star *}$ & 4.612 & 0.121 & 0.124 \\
\hline Content Likeability $\rightarrow$ Content Credibility & $0.656^{\star \star \star}$ & 11.389 & $0.682^{* \star \star}$ & 10.234 & 0.027 & 0.623 \\
\hline $\begin{array}{l}\text { Content Likeability } \rightarrow \text { Social Media } \\
\text { Engagement }\end{array}$ & $0.643^{* * *}$ & 16.887 & $0.501^{* * *}$ & 8.293 & $0.142^{*}$ & 0.020 \\
\hline
\end{tabular}

Remark: ${ }^{\star * *} p$-value $<0.001,{ }^{* *} p$-value $<0.01,{ }^{*} p$-value $<0.05$ 


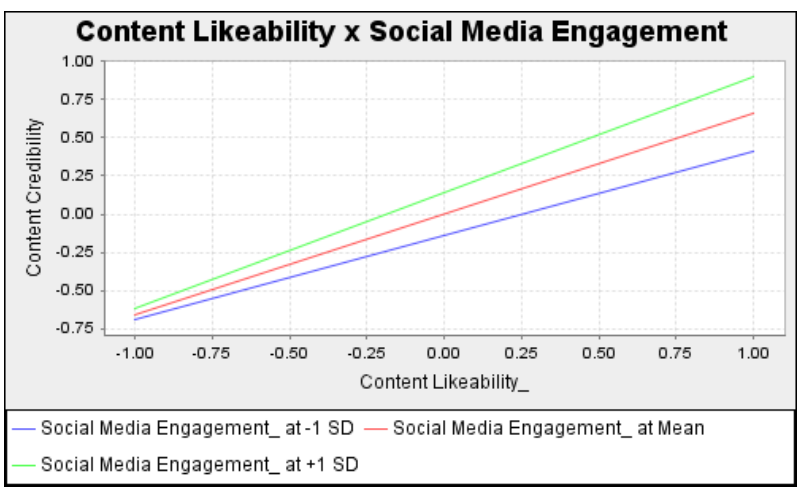

(a) Young adults

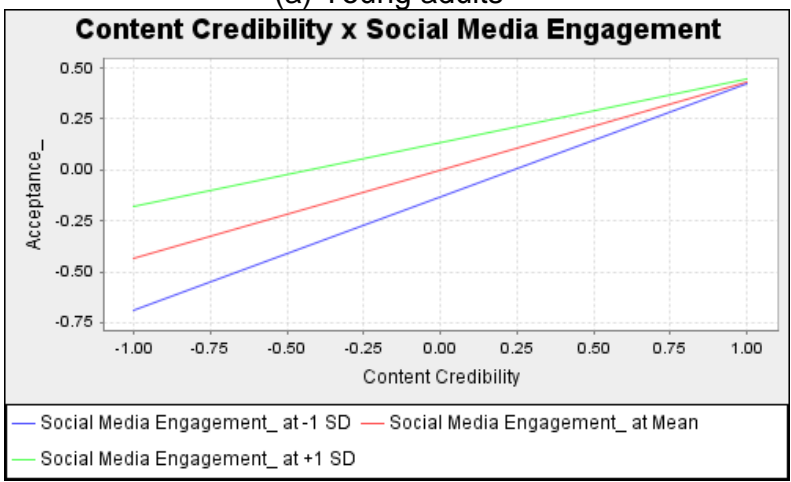

(c) Middle-aged adults

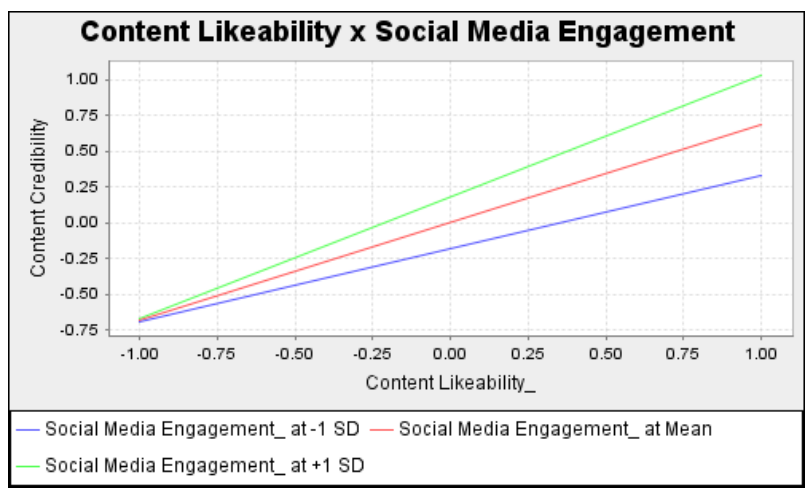

(b) Middle-aged adults

Figure 5: Interaction effects for young and middle-aged adults

\section{Discussions and Conclusion}

This section firstly describes the theoretical contributions and practical implications. Then, the limitations of the study are discussed and further studies are recommended.

\subsection{Contribution to Theory}

This study aims to examine the relationships between content likeability, content credibility, social media engagement, and user acceptance of product placement in mobile social networks. The results indicate that content likeability takes a major role in (directly and indirectly) influencing users' acceptance of product placement in mobile social networks (total effect $=0.736$, as shown in Table 9). Social media engagement and content credibility are mediators between content likeability and user acceptance of product placement in mobile social networks. When a user likes the messages posted on a mobile social network a lot, he/she will engage in that mobile social network. Then, the user will believe the (product) information posted on that mobile social network. Finally, he/she will accept the product placements (advertising) in that mobile social network. This study contributes a research model that explains the relational flow from content likeability of a mobile social network to the user acceptance of product placement in that network via social media engagement and content credibility of the network. This model extends our knowledge in social media engagement theory that users perceive likeable contents which being their specific interests, these likeable contents attract users to check and reply to messages posted on mobile social media frequently. Thus, high likeable contents result in high user engagement in mobile social networks. On the other hand, product placement in traditional media is carried in a passive setting (such as movies). The product placement in mobile social networks involves the social interactions between friends. Coker and Altobello [12] found that interaction enhances recall of placed brands among friend dyads. Since a mobile social network is a social setting, the results of this study imply that user engagement in a social setting should enhance the effect of product placement in that social setting. This study extends the application of the social media engagement theory to study product placement in social media. 
Table 9: Total effects

\begin{tabular}{|l|l|l|l|}
\hline & Acceptance & Content Credibility & Social Media Engagement \\
\hline Content Credibility $x$ Social Media Engagement & -0.039 & & \\
\hline Content Credibility & 0.385 & & \\
\hline Social Media Engagement & 0.202 & 0.157 & \\
\hline Content Likeability x Social Media Engagement & 0.054 & 0.140 & \\
\hline Content Likeability $x$ Social Media Engagement_ & 0.017 & & \\
\hline Content Likeability & 0.736 & 0.770 & 0.594 \\
\hline
\end{tabular}

The results also indicate that there is an interaction effect of social media engagement and content likeability on the content credibility of mobile social networks (as shown in Figure 3). If a user who shows a higher level of engagement in a mobile social network, the effect of content likeability on the content credibility of the mobile social network will be higher. This result is reasonable because the chance for a user to read a likeable content will be increased if he/she frequently checks the messages posted in a mobile social network. People believe the likeable contents. So a higher level of content credibility will be built from a high level of social media engagement with a high level of content likeability. However, if a user who seldom read messages posted on the social media, the chance that he/she can observe a likeable content will be comparatively lower. It is because the old contents (include high liked contents) will rapidly be replaced by new contents. Therefore, a lower level of social media engagement reduces the effect of content likeability on the content credibility of a mobile social network. Most of the previous studies in social media engagement only tested its direct and/or mediating effects on its consequences. This finding may be the first that empirically indicates the moderating role of social media engagement between its antecedent and consequence. It enriches researchers' thinking for designing their research model of social media engagement research.

The results of PLS-MGA indicate that the effect of content likeability on social media engagement for young adults is higher than for middle-aged adults. Since middle-aged adults are more mature than young adults and they have less spare time than young people, they are less easy to engage to a mobile social network even if they like the contents on the network. Furthermore, the interaction effect of content credibility and social media engagement on user acceptance of product placement in mobile social networks for young adults is positive (not significant), but this interaction effect for middle-aged adults is negative (significant). Therefore, for middle-aged adults, if the level of content credibility of a mobile social network is high, the level of acceptance of product placements is less influenced by user engagement (right-hand side of Figure 5c). On the other hand, when the level of content credibility of a mobile social network is low, the level of acceptance of product placements will be affected by the level of user engagement (left-hand side of Figure 5c). In Figure 4b (middle-aged adults), the effect of content credibility on user acceptance $(\beta=0.435)$ is higher than the effects of other factors. In Figure 4a (young adults), the effect of content likeability on user acceptance $(\beta=0.420)$ is higher than the effect of content credibility $(\beta=0.325)$. The number of likes is an indicator of content likeability. However, it is just a facade. Young adults make judgment relied on this facade of explicit information, so they would accept a product that its content is likeable. However, middle-aged adults would also consider implicit aspects when making a judgement, so they would evaluate the content credibility of messages more than the content likeability of messages on the mobile social networks. Hence, the content credibility of a mobile social network takes an important role in influencing middle-aged adults' behaviour towards the product placement in mobile social networks. This study contributes to our knowledge of middle-aged adults' online behaviours.

The literature reveals that the effect of content likeability of social media on user behaviors has not been well studied yet. We know little of content likeability of a mobile social network. This study is an exploratory study that helps us to explore the theory of content likeability and have a better understanding of content likeability of mobile social networks on user behaviours. This study establishes a measurement scale for measuring content likeability of mobile social networks by using a focus group study and followed by a questionnaire survey (see Appendix A). This study explores the concept of content likeability of mobile social networks and contributes a measurement scale for measuring the content likeability of mobile social networks. Researchers can apply this measurement scale for their further research in studying content likeability of mobile social networks and even other social networks.

\subsection{Implications for Practice}

Most of the social media marketing companies employ large numbers of soldiers to post and push the messages on social media without knowing the theory behind it. This study explains the mechanism of building user behaviour toward product placement in mobile social media. Pushing posted messages by placing likes is the initial step in building up the content likeability. However, the results of this study indicate that building user engagement is also important. That is what most of the social media marketers don't know. It also explains why they fail to market their brands and products. Since the operators of mobile social networks are already thinking how to engage fans on the mobile social networks such as developing more features and activities, the social media marketers could sponsor red pockets (gifts) to promote those social media engagement activities in order to make product placements more effective. 
Of course, the content credibility of a social network is also important. It indicates whether the contents on a social network are believable. Raghupathi and Fogel [67] found that the advertisements seen on Facebook were in one's truthful were significantly associated with increasing intention to purchase the advertised product. In case most of the contents posted on a mobile solid network are valuable, wonderful, personally agreeable, and impressive, members of that social network would perceive the contents in that network are more believable. Therefore, mobile social media marketers should spend their effort in building a believable network rather than just frequently post meaningless posts and generate a huge of likes for those meaningless messages. That kind of marketing actions could only destroy the content credibility of the social networks.

\subsection{Limitations and Further Studies}

There is a limitation in the design of measurement instruments. Since this study is an exploratory study, so it only tested the interrelationship of four single-dimensional constructs of the research model. Researchers are recommended to develop multi-dimensional constructs to further evaluate this research model in different settings.

This study only considers three factors that influence the user acceptance of product placement in mobile social networks. Researchers can extend this research model with other variables to study user behaviours that are not limited to the acceptance of product placement in mobile social media.

There is a limitation in the development of the measurement scale of content likeability. The scale development process was conducted in Chinese (see Appendix). There is an advantage that the words in Chinese were clearer meanings for respondents. Since the meanings of six selected items in English are not overlapped, therefore, there should be no threat to the validity of the study. However, for further studies in other countries, researchers may need to refine this scale.

Due to the limitation of the research resources, this study only collected data from the users of WeChat in China. Therefore, the results of this study may not generalizable to other mobile social media in other countries. Further studies are recommended to investigate in different mobile social media in other countries.

\section{References}

[1] E. Babacan, S.I. Akcalu and E.P. Baytekin, Product placement as a rising marketing communication activity: Assessment on television serials, Procedia-Social and Behavioral Sciences, vol. 62, pp. 1319-1331, 2012.

[2] J. Bardzell, S. Bardzell, T. Pace, and J. Karnell, Intuitive interaction applied to interface design, in Proceedings of the International Design Congress, IASDR 2005, Douliou, Taiwan, 2005, pp. 1-10.

[3] V. Barger, J.W. Peltier and D.E. Schultz, Social media and consumer engagement: A review and research agenda, Journal of Research in Interactive Marketing, vol. 10, no. 4, pp. 268-287, 2016.

[4] P.M. Bentler and C.P. Chou, Practical issues in structural modelling, Sociological Methods and Research, vol. 16, no. 1, pp. 78-117, 1987.

[5] R.J. Brodie, L.D. Hollebeek, B. Juric, and A. llic, Customer engagement: Conceptual domain, fundamental propositions, and implications for research, Journal of Service Research, vol. 14, no. 3, pp. 252-271, 2011.

[6] R.J. Brodie, A. Ilic, B. Juric, and L.D. Hollebeek, Consumer engagement in a virtual brand community: An exploratory analysis, Journal of Business Research, vol. 66, no. 1, pp. 105-114, 2013.

[7] S.L. Brodsky, T.M.S. Neal, R.J. Cramer, and M.H. Ziemke, Credibility in the courtroom: How likeable should an expert witness be?, Journal of the American Academy of Psychiatry and the Law, vol. 37, no. 4, pp. 525-532, 2009.

[8] B.J. Calder and E.C. Malthouse, Media engagement and advertising effectiveness, in Kellogg on Advertising and Media (B.J. Calder, Ed.). Hoboken, NJ: Wiley, 2008, pp. 1-36.

[9] C.M.K. Cheung, M.K.O. Lee and X.L. Jin, Customer engagement in an online platform: A conceptual model and scale development, in Proceedings of the Thirty-Second International Conference on Information Systems (ICIS), Shanghai, China, 2011, pp. 3105-3112.

[10] R.B. Cialdini, Influence: Science and Practice (3rd ed.). New York: Harper Collins, 1993

[11] K.K. Coker and S.A. Altobello, Product placements in social settings: The impact of coviewing on the recall of placed brands, Journal of Business Research, vol. 87, pp. 128-136, 2018.

[12] N.J. De Vries and J. Carlson, Examining the drivers and brand performance implications of customer engagement with brands in the social media environment, Journal of Brand Management, vol. 21, no. 6, pp. 495-515, 2014

[13] L. De Vries, S. Gensler and P.S.H. Leeflang, Popularity of brand posts on brand fan pages: An investigation of the effects of social media marketing, Journal of Interactive Marketing, vol. 26 no. 2, pp. 83-91, 2012.

[14] L. Dessart, C. Veloutsou and A. Morgan-Thomas, Consumer engagement in online brand communities, The Journal of Product and Brand Management, vol. 24, no. 1, pp. 28-42, 2015.

[15] V. Devika and S. Sreejesh, Effects of brand placement strength, prior game playing experience and game involvement on brand recall in advergames, Journal of Indian Business Research, vol. 7, no. 3, pp. 292-312, 2015.

[16] P.M. Di Gangi and M.M. Wasko, Social media engagement theory: Exporing the influence of user engagement on social media usage, Journal of Organizational and End User Computing, vol. 28 no. 2, pp. 53-73, 2016. 
[17] J.A. Dias, J.G. Dias and C. Lages, Can negative characters in soap operas be positive for product placement?, Journal of Business Research, vol. 71, pp. 125-132, 2017

[18] M.J. Dutta-Bergman, The impact of completeness and web use motivation on the credibility of e-health information, Journal of Communication, vol. 54, no. 2, pp. 253-269, 2004.

[19] U. Evers and P. Harrigan, Consumer brand engagement with tourism organisations on social media, in Proceedings of Australian and New Zealand Marketing Association Conference, Sydney, Australia, 2015, pp. 898-904

[20] L. Gageler and J. van der Schee, Product placement on social media: A study on how generation Y's brand perception and purchase intention are influenced, M.S. Thesis, Jonkoping International Business School, Jonkoping University, Jonkoping, 2016.

[21] H. Gangadharbatla, A comparison of in-game brand placement for active versus passive players, Journal of Interactive Advertising, vol. 16, no. 2, pp. 117-132, 2016.

[22] C. Gerlitz and A. Helmond, The like economy: Social buttons and the data-intensive web, New Media \& Society, vol. 15, no. 8, pp. 1348-1365, 2013.

[23] R. Gommans, M.J. Sandstrom, G.W.J.M. Stevens, T.F.M. ter Bogt, and A.H.N. Cillessen, Popularity, likeability, and peer conformity: Four field experiments, Journal of Experimental Social Psychology, vol. 73, pp. 279-289, 2017.

[24] J.D. Greer, Evaluating the credibility of online information: A test of source and advertising influence, Mass Communication \& Society, vol. 6, no. 1, pp. 11-28, 2003.

[25] S. Greenwood, A. Perrin and M. Duggan. (2016, November) Social media update 2016. Pew Research Center. [Online]. Available: http://www.pewinternet.org/2016/11/11/social-media-update-2016/

[26] Y.W. Ha, M.C. Park and E. Lee, A framework for mobile SNS advertising effectiveness: User perceptions and behaviour perspective, Behaviour and Information Technology, vol. 33, no. 12, pp. 1333-1346, 2014.

[27] J.F. Jr. Hair, M. Sarstedt, C.M. Ringle, and J.A. Mena, An assessment of the use of partial least squares structural equation modeling in marketing research, Journal of the Academy of Marketing Science, vol. 40, no. 3, pp. 414-433, 2012.

[28] J.F. Jr. Hair, G.T.M. Hult, C.M. Ringle, and M. Sarstedt, A Primer on Partial Least Squares Structural Equation Modeling (PLS-SEM), 2nd Edition. Thousand Oaks: Sage, 2017.

[29] K.N. Hampton, L.S. Goulet, C. Marlow, and L. Rainie. (2012) Why most Facebook users get more than they give: The effect of Facebook power users on everybody else. Pew Research Center. [Online]. Available: https://www.academia.edu/2449652/Why Most Facebook Users Get More Than They Give The Effect of Facebook Power Users on Everybody Else

[30] H. Han and S. Trimi, Social commerce design: A framework and application, Journal of Theoretical and Applied Electronic Commerce Research, vol. 12, no. 3, pp. 50-68, 2017.

[31] P. Harrigan, U. Evers, M. Miles, and T. Daly, Customer engagement with tourism social media brands, Tourism Management, vol. 59, pp. 597-609, 2017.

[32] L.D. Hollebeek, M.S. Glynn and R.J. Brodie, Consumer brand engagement in social media: Conceptualization, scale development and validation, Journal of Interactive Marketing, vol. 28, no. 2, pp. 149-165, 2014.

[33] M.G. Hughes, J.A. Griffith, T.A. Zeni, M.L. Arsenault, O.D. Cooper, G. Johnson, J.H. Hardy, S. Connelly, and M.D. Mumford, Discrediting in a message board forum: The effects of social support and attacks on expertise and trustworthiness, Journal of Computer-Mediated Communication, vol. 19, no. 3, pp. 325-341, 2014.

[34] Y.L. Hwong, C. Oliver, M.V. Kranendonk, C. Sammut, and Y. Seroussi, What makes you tick? The psychology of social media engagement in space science communication, Computers in Human Behavior, vol. 68, pp. 480$492,2017$.

[35] J. Ihm, Network measures to evaluate stakeholder engagement with nonprofit organizations on social networking sites, Public Relations Review, vol. 41, no. 4, pp. 501-503, 2015.

[36] T.J. Johnson and B.K. Kaye, Reasons to believe: Influence of credibility on motivations for using social networks, Computers in Human Behavior, vol. 50, pp. 544-555, 2015.

[37] T.J. Johnson and B.K. Kaye, Some like it lots: The influence of interactivity and reliance on credibility, Computers in Human Behavior, vol. 61, pp. 136-145, 2016.

[38] A.M. Kaplan and M. Haenlein Users of the world, unite! The challenges and opportunities of social media, Business Horizons, vol. 53, no. 1, pp. 59-68, 2010.

[39] W. Kahn, Psychological conditions of personal engagement and disengagement at work, Academy of Management Journal, vol. 33, no. 4, pp. 629-724, 1990.

[40] P. Kardos, Z. Unoka, C. Pleh, and P. Soltesz, Your mobile phone indeed means your social network: Priming mobile phone activates relationship related concepts, Computer in Human Behavior, vol. 88, pp. 84-88, 2018.

[41] V.J. Karisik, 20 years of research on product placement in movie, television and video game media, Journal of Economic and Social Studies, vol. 4, no. 2, pp. 253-283, 2014

[42] J.A. Karrh, Brand placement: A review, Journal of Current Issues and Research in Advertising, vol. 20, no. 2, pp. 31-49, 1998

[43] D.T. Kenrick, S.L. Neuberg and R.B. Cialdini, Social Psychology: Unraveling the Mystery. (2nd ed.). Boston, MA: Allyn \& Bacon, 2002.

[44] E. Kim, J.S. Lin and Y. Sung, To app or not to app: Engaging consumers via branded mobile apps, Journal of Interactive Advertising, vol. 113, no. 1, pp. 54-65, 2013.

[45] S. Kiousis, Public trust or mistrust? Perceptions of media credibility in the information age, Mass Communication \& Society, vol. 4, no. 3, pp. 381-403, 2001. 
[46] N. Kock and G.S. Lynn, Lateral collinearity and misleading results in variance-Based SEM: An illustration and recommendations, Journal of the Association for Information Systems, vol. 13, no. 7, pp. 546-580, 2012

[47] H. Lee, S.Y. Choi and Y.S. Kang, Formation of e-satisfaction and repurchase intention: moderating roles of computer self-efficacy and computer anxiety, Expert Systems with Applications, vol. 36, no. 4, pp. 7848-7859, 2009.

[48] R. Li and A. Suh, Factors influencing information credibility on social media platforms: Evidence from Facebook pages, in Proceedings Third Information Systems International Conference, Procedia Computer Science, vol. 72, Shenzhen, China, 2015, pp. 314-328.

[49] J.W. Lian and D.C. Yen, Online shopping drivers and barriers for older adults: age and gender differences, Computers in Human Behavior, vol. 37, pp. 133-143, 2014.

[50] A.R.D. Liang, T.Y. Hsiao and C.H. Cheng, The effects of product placement and television drama types on the consumer responses of college students, Asia Pacific Journal of Tourism Research, vol. 20, no. 11, pp. 12121233, 2015.

[51] Z. Liu, Perceptions of credibility of scholarly information on the web, Information Processing and Management, vol. 40, no. 6, pp. 1027-1038, 2004.

[52] S.H. Liu, C.H. Chou and H.L. Liao, An exploratory study of product placement in social media, Internet Research, vol. 25, no. 2, pp. 300-316, 2015.

[53] R.J. Lutz, Affective and cognitive antecedents of attitude toward the ad: A conceptual framework, in Psychological Processes and Advertising Effects (L. Alwitt and A. Mitchell, Eds.). Hillsdale, NJ: Erlbaum, 1985, pp. 45-63.

[54] R.W. Mack, J.E. Blose and B. Pan, Believe it or not: Credibility of blogs in tourism, Journal of Vacation Marketing, vol. 14, no. 2, pp. 133-144, 2008.

[55] K. Makri and B.B. Schlegelmilch, Time orientation and engagement with social networking sites: A crosscultural study in Austria, China and Uruguay, Journal of Business Research, vol. 80, pp. 155-163, 2017.

[56] A. Marchand, T. Hennig-Thurau and S. Best, When James Bond shows off his Omega: Does product placement affect its media host?, European Journal of Marketing, vol. 49, no. 9/10, pp. 1666-1685, 2015.

[57] J. Martí-Parreño, J. Bermejo-Berros and J. Aldás-Manzano, Product placement in video games: The effect of brand familiarity and repetition on consumers' memory, Journal of Interactive Marketing, vol. 38, pp. 55-63, 2017.

[58] D.H. McKnight and C.J. Kacmar, Factors and effects of information credibility, in Proceedings of the 9th International Conference on Electronic Commerce, ACM Press, New York, 2007, pp. 423-432.

[59] J. Meyer, R. Song and K. Ha, The effect of product placements on the evaluation of movies, European Journal of Marketing, vol. 50, no. 3/4, pp. 530-549, 2016.

[60] J.L. Monahan, I don't know it but I like you-the influence of non-conscious affect on person perception, Human Communication Research, vol. 24, no. 4, pp. 480-500, 1998.

[61] V. Noguti and C.A. Russell, Normative influences on product placement effects: Alcohol brands in television series and the influence of presumed influence, Journal of Advertising, vol. 43, no. 1, pp. 46-62, 2014.

[62] Oxford Living Dictionaries. (2017) Definition of likeable in English. Lexico. [Online]. Available: https://en.oxford dictionaries.com/definition/likeable

[63] M. Pagani and A. Mirabello, The influence of personal and social-interactive engagement in social TV web sites, International Journal of Electronic Commerce, vol. 16, no. 2, pp. 41-67, 2012.

[64] S. Papagiannidis, E. See-To and M. Bourlakis, Virtual test-driving: The impact of simulated products on purchase intention, Journal of Retailing and Consumer Services, vol. 21, no. 5, pp. 877-887, 2014.

[65] C.W. Phang, C. Zhang and J. Sutanto, The influence of user interaction and participation in social media on the consumption intention of niche products, Information \& Management, vol. 50, no. 8, pp. 661-672, 2013.

[66] G. Prendergast, P.Y. Liu and D.T.Y. Poon, A Hong Kong study of advertising credibility, Journal of Consumer Marketing, vol. 26, no. 5, pp. 320-329, 2009.

[67] V. Raghupathi and J. Fogel, The impact of opinion leadership on purchases through social networking websites, Journal of Theoretical and Applied Electronic Commerce Research, vol. 10, no. 3, pp. 18-29, 2015.

[68] S. Reysen, Construction of a new scale: The Reysen likeability scale, Social Behavior and Personality, vol. 33, no. 2, pp. 201-208, 2005

[69] C.M. Ringle, S. Wende and J.M. Becker. (2015) SmartPLS 3, Boenningstedt: SmartPLS GmbH. SmartPLS. [Online]. Available: http://www.smartpls.com.

[70] T. Robbins and A. DeNisi, A closer look at interpersonal affect as a distinct influence on cognitive processing in performance evaluations, Journal of Applied Psychology, vol. 79, no. 3, pp. 341-353, 1994

[71] S.M. Shariff, X.J. Zhang and M. Sanderson, On the credibility perception of news on Twitter: Readers, topics and features, Computers in Human Behavior, vol. 75, pp. 785-796, 2017.

[72] S. Shavitt and T.C. Brock, Persuasion - Psychological Insights and Perspectives. Massachusetts: Allyn and Bacon, 1994

[73] K.K.F. So, C. King and B. Sparks, Customer engagement with tourism Brands: Scale development and validation, Journal of Hospitality \& Tourism Research, vol. 38, no. 3, pp. 304-329, 2014.

[74] I. Spero and M. Stone, Agents of change: How young consumers are changing the world of marketing, Qualitative Market Research: An International Journal, vol. 7, no. 2, pp. 153-159, 2004.

[75] Statista. (2019, November) Number of monthly active WeChat users from 3rd quarter 2012 to 2nd quarter 2019 (in millions). Statista. [Online]. Available: https://www.statista.com/statistics/255778/number-of-active-wechatmessenger-accounts/ 
[76] Statista. (2019, August) Number of monthly active WhatsApp users worldwide from April 2013 to December 2017 (in millions). Statista. [Online]. Available: https://www.statista.com/statistics/260819/number-of-monthlyactive-whatsapp-users/

[77] A.T. Stephen and L.V. Coote, Brands in action: The role of brand placements in building consumer-brand identification, in Proceedings of the American Marketing Association Conference, Chicago, IL, USA, vol. 16, 2005, p. 28

[78] S.S. Sundar, Social psychology of interactivity in human-website interaction, in The Oxford Handbook of Internet Psychology (A.N. Joinson, Ed.). Oxford, United Kingdom: Oxford University Press, 2007, pp. 89-104.

[79] R. Thakur, Understanding customer engagement and loyalty: A case of mobile devices for shopping, Journal of Retailing and Consumer Services, vol. 32, pp. 151-163, 2016.

[80] K.B. Tompkins, D.M. Martz, C.A. Rocheleau, and D.G. Bazzini, Social likeability, conformity, and body talk: Does fat talk have a normative rival in female body image conversations? Body Image, vol. 6 no. 4, pp. 292298, 2009.

[81] S. Tseng and B.J. Fogg, Credibility and computing technology, Communication of the ACM, vol. 42 no. 5, pp. 39-44, 1999.

[82] R. Wang, J. Kim, A. Xiao, and Y.J. Jung, Networked narratives on Humans of New York: A content analysis of social media engagement on Facebook, Computers in Human Behavior, vol. 22, pp. 149-153, 2017.

[83] $\mathrm{L}$. Wu, Understanding the impact of media engagement on the perceived value and acceptance of advertising within mobile social networks, Journal of Interactive Marketing, vol. 16, no. 1, pp. 59-73, 2016.

[84] M. Zhang, L. Guo, M. Hu, and W. Liu, Influence of customer engagement with company social networks on stickiness: Mediating effect of customer value creation, International Journal of Information Management, vol. 37, no. 3, pp. 229-240, 2017. 


\section{Appendix A: Ranking of Measurable Items for Content Likeability}

In this study, content likeability of a mobile social network is the judgement of the content posted on a mobile social network that makes people easily like. So, the measurable items of content likeability are the content of something which people give a like after reading or watching it on mobile social networks. Among the mobile social networks, WeChat has a powerful feature called Moments that supports users to post text, article, image, music, and video, as well as comment and like on the Moments. This feature is very suitable for product placement advertising. Since WeChat is the most popular mobile social medium in China, this study uses WeChat groups to represent the mobile social networks in China. First, a focus group was formed to list most of the possible situations that people would give a like on a post in a mobile social network. The focus group included two academia, three young adults, and three middle-aged adults. All of them have good social networking experiences. After a two-hour meeting, 26 potential measurable items (in Chinese) were established. Then, an online survey was conducted for rating these 26 items through WeChat in April 2017. The respondents were allowed to select (tick $=1$, no tick $=0$ ) maximum ten situations they would give a like on a post on the WeChat. Totally 132 people have participated in this survey and the results were shown in below figure. Finally, the top six items ( $>=50 \%$ respondents selected) were used as the measurable items of content likeability for this study. The six items are: I would give a like when the content on a mobile social medium is valuable, wonderful, personally agreeable, impressive, useful, and warm.

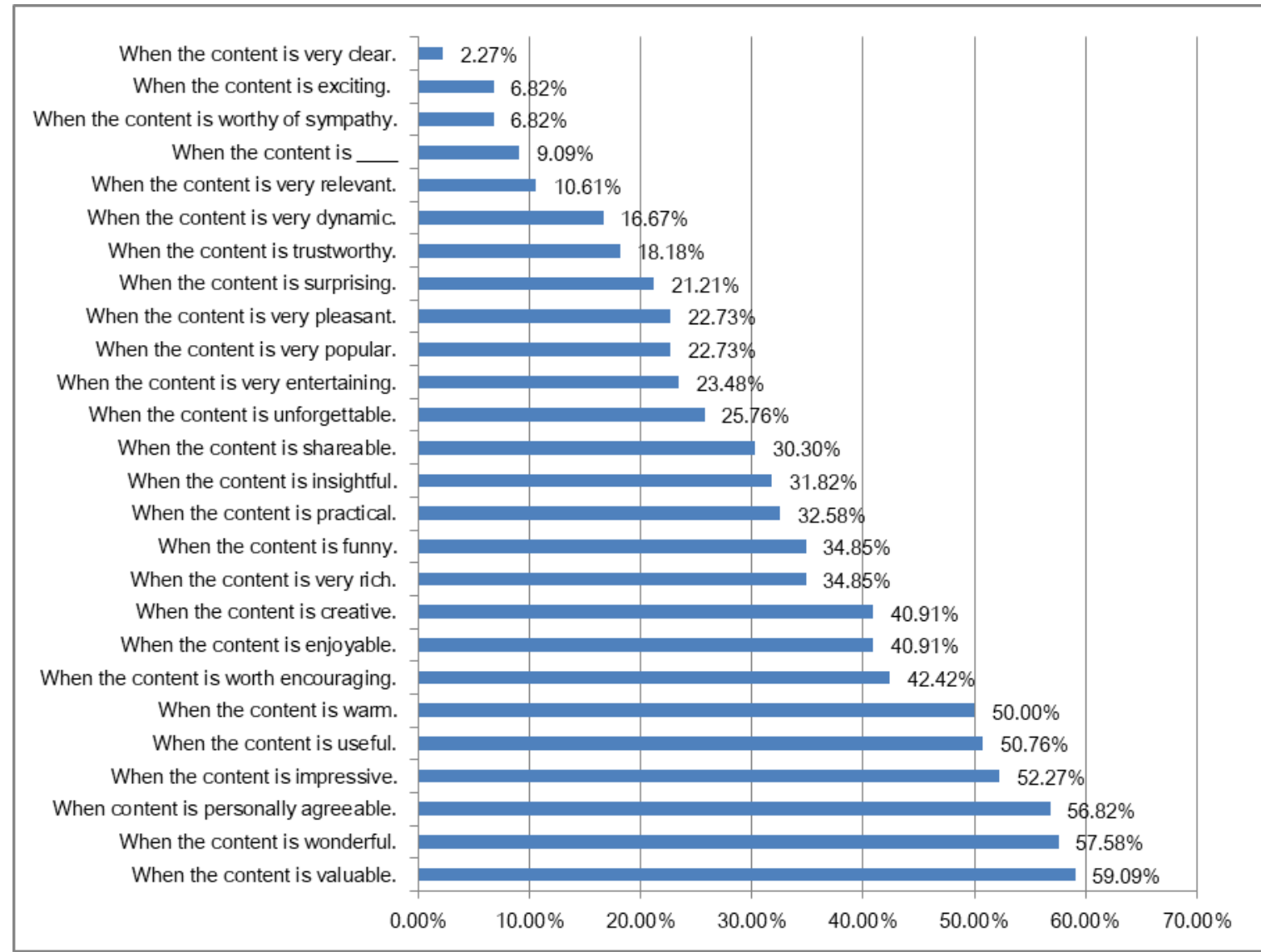




\section{Appendix B: An Example of Product Placement in Mobile Social Networks}

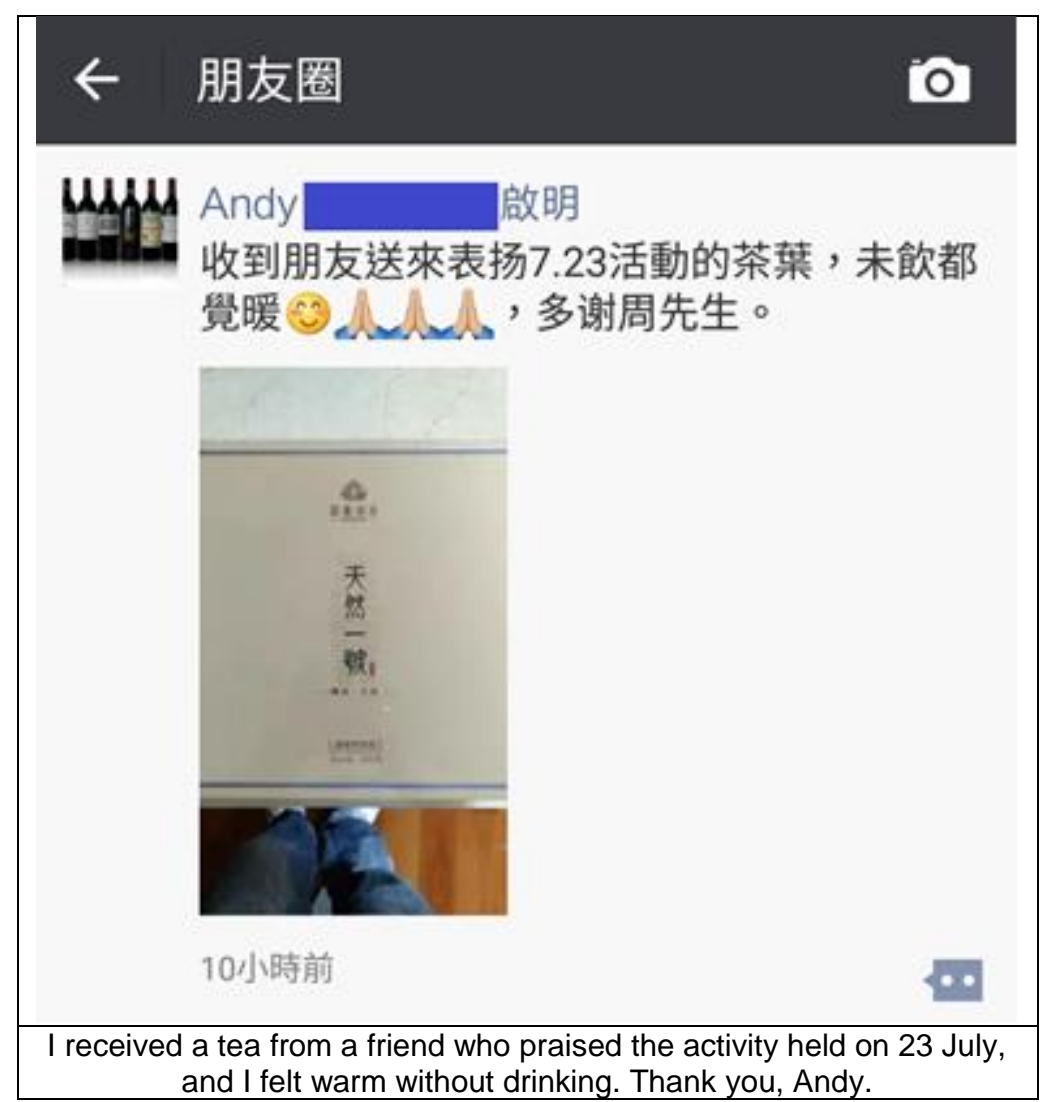

